\title{
25-hydroxyvitamin D levels are low but not associated with disease activity in chronic spontaneous urticaria and depression
}

\author{
Vurgun $E^{\mathrm{a}, 1}$, Memet $\mathrm{B}^{\mathrm{b}, 2}$, Kocaturk $E^{\mathrm{b}, 2}$, Guntas $\mathrm{G}^{\mathrm{a}, \mathrm{c}}$ \\ Medical Biochemistry, Sorgun State Hospital, Yozgat, Turkey. eren_vurgun@hotmail.com
}

\begin{abstract}
AIM: To evaluate vitamin D levels in patients with chronic spontaneous urticaria (CSU), depression and both of them, thus to find out whether vitamin D may be a common causative factor of CSU and depression. METHODS: Thirty patients with CSU, 30 patients with depression, 30 patients with both CSU and depression and 30 healthy volunteers as control group were involved in the study. Serum 25 -hydroxyvitamin D $(25(\mathrm{OH})$ D) levels of these groups were measured and compared. Correlations between 25(OH)D levels and the activity of CSU and depression were analyzed.

RESULTS: Healthy controls' $25(\mathrm{OH}) \mathrm{D}$ levels $(17.2 \pm 8.8 \mathrm{ng} / \mathrm{mL})$ were higher than patients with CSU $(9.1 \pm 5.1$ $\mathrm{ng} / \mathrm{mL})$, depression $(8.9 \pm 6.1 \mathrm{ng} / \mathrm{mL})$ and CSU with depression $(7.7 \pm 4.7 \mathrm{ng} / \mathrm{mL})(p<0.001, p<0.001$ and $p<0.001$, respectively). There were no differences in $25(\mathrm{OH}) \mathrm{D}$ levels between CSU patients with and without depression, between depression patients and CSU patients with and without depression $(p=0.43, p=0.82$ and $p=0.92$, respectively). There were no correlations between $25(\mathrm{OH}) \mathrm{D}$ levels and the activity of CSU or depression ( $p=0.99$ and $p=0.76$, respectively).

CONCLUSION: Lower 25(OH)D levels in CSU and/or depression may appear as a secondary phenomenon, which means being result of these diseases rather than the cause (Tab. 1, Fig. 2, Ref. 41). Text in PDF www.elis.sk

KEY WORDS: vitamin D, vitamin D deficiency, chronic urticaria, depression.
\end{abstract}

\section{Introduction}

Urticaria is a disorder characterized by the appearance of wheal and flare reaction lasting less than 24 hours (1). The disease is termed as acute urticaria if it lasts less than six weeks and chronic urticaria if it lasts longer than six weeks and with almost every day presentation (2). The primary effector cell is the mast cell and the main mediator is histamine (3). Basophils also contain histamine, but the most important source of histamine are the skin mast cells (2).

Although the central role of vitamin D in bone physiology is well known, it has been reported to show various immunomodulatory actions on both natural and acquired immunity via plasma membrane (mVDR) and nuclear (nVDR) receptors on the epithe-

aDepartment of Medical Biochemistry, Okmeydani Training and Research Hospital, Istanbul, Turkey, ${ }^{1}$ Medical Biochemistry, Sorgun State Hospital,

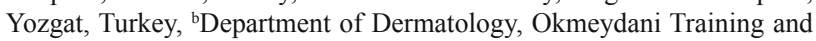
Research Hospital, Istanbul, Turkey, ${ }^{2}$ Department of Dermatology, Koc University School of Medicine, Istanbul, Turkey, and 'Kurklareli University School of Health, Kirklareli, Turkey

Address for correspondence: E. Vurgun, Medical Biochemistry, Sorgun State Hospital, postal code: 66700, Yozgat, Turkey.

Phone: +905377188596 lial cells, monocytes, macrophages, $\mathrm{T}$ and B lymphocytes, dendritic cells and mast cells $(4,5)$. In addition to its roles in other parts of immune system, it has also been shown that vitamin D affect the proliferation, survival, differentiation and function of the mast cells $(4,6)$.

Chronic urticaria is often associated with psychological conditions such as depression, anxiety and stress, which may play a role not only in the genesis of the disease but also in its evolution (7). Depression is strongly associated with morbidity, mortality and health expenditures. Although biological, physiological, and environmental theories have been developed, the underlying pathophysiology of depression is still not fully understood, and it is likely that more than one different mechanism plays a role in the pathogenesis (8).

Vitamin D receptors are found on neurons and glial cells which are located in many brain regions including the cingulate cortex and the hippocampus which are involved in the pathophysiology of depression (9). The presence of vitamin D in a number of brain processes such as neuroimmunomodulation, regulation of neurotrophic factors, neuroprotection, neuroplasticity and brain development makes biologically reasonable that vitamin D might have an implication on the occurrence of depression (10). Vitamin D is a unique neurosteroid hormone that may have an important role in the pathogenesis of depression. 
Tab. 1. Comparative table of demographic characteristics of groups.

\begin{tabular}{lcccc}
\hline & Control & Depression & CSU without depression & CSU with depression \\
\hline $\mathrm{n}$ & 30 & 30 & 30 & 30 \\
Age & $32(26.7-35.7)$ & $34.5(25.7-43.2)$ & $41.5(31.7-58.2)^{*}$ & $40.5(32.7-53.7)^{* \Delta}$ \\
Female/Male & $22 / 8$ & $27 / 3$ & $22 / 8$ & $28 / 2$ \\
UAS7 score & - & - & $14(5.0-28.5)$ & $22.5(14.7-38.0)^{\#}$ \\
BDI score & $7(2.7-9.2)$ & $28(24.7-38)^{* * \#}$ & $7(2.7-9.2)$ & $27.5(24-32.7)^{* * \#}$ \\
\hline$* \mathrm{p}<0.05$ and ${ }^{* *} \mathrm{p}<0.001$ when compared to control group, ${ }^{\Delta} \mathrm{p}<0.05$ when compared to depression group, \\
${ }^{*} \mathrm{p}<0.05$ and ${ }^{\# \#} \mathrm{p}<0.001$ when compared to CSU without depression group
\end{tabular}

The first aim of this study was to determine vitamin D levels in patients with chronic spontaneous urticaria (CSU), depression and both of them and to compare them with healthy controls. The second aim was to investigate the relationships between 25-hydroxyvitamin D $(25(\mathrm{OH}) \mathrm{D})$ levels and the activity of CSU and depression, thus to find out whether vitamin D may be a common causative factor of CSU and depression.

\section{Methods}

\section{Participants}

The study was conducted at the Dermatology Clinic of Okmeydani Training and Research Hospital which is an Urticaria Centre of Reference and Excellence (UCARE) (11) between September 2015 and March 2016. All patients who were volunteered to participate in the study were administered a Beck Depression Inventory (BDI) (12). Thirty CSU patients whose scores were < 17 points on the BDI were included in the study as "CSU without depression". The CSU patients whose scores were $\geq 17$ points on the BDI were directed to the psychiatry clinic. Thirty patients who were diagnosed as depression by the psychiatrist were included in the study as "CSU with depression". All CSU patients' urticaria activity scores of last seven days (UAS7) (13) at the time of enrollment to the study were recorded.

Thirty patients whose scores were $\geq 17$ points on the BDI and who were diagnosed with depression by the psychiatrist from the Psychiatry Clinic of our hospital were included in the study as "depression group". In addition, thirty healthy volunteers who had < 17 points on the BDI were included in the study as "control group". All participants were between 18-64 years old and have not taken any vitamin D supplementation within last six months. CSU patients who were enrolled into the study were taking antihistamine treatment alone. Subjects who were on continuous corticosteroid or immunosuppressive treatment or on regular non-steroid antiinflammatory drugs or on antidepressants for the last six months were not included in the study.

\section{Measurement of 25(OH)D}

Serum 25(OH)D levels were measured by using Zivak 25-OH Vitamin D2/D3 LC-MS/MS analysis kit (Zivak Technologies, Istanbul, Turkey) in fully automated Zivak Multitasker LC-MS/ MS (Zivak Technologies, Istanbul, Turkey) (14). Inter-assay and intra-assay CVs for 25(OH)D measurement were $\leq 3.4 \%$ and $\leq$ $4.4 \%$, respectively.

\section{Ethical considerations}

This study was conducted in accordance with the Declaration of Helsinki, and ethical approval was obtained from Okmeydani Training and Research Hospital Ethics Committee of Clinical Investigations (No: 522).

\section{Statistical analysis}

Thirty participants were included in each group for the effect size of 0.65 with type I error rate of 0.05 and type II error rate of 0.20 . Sample size was calculated by G*Power 3.1 (GPower, Dusseldorf, Germany).

Age, UAS7 and BDI scores were not normally distributed, so they were expressed as median (25-75 percentile). Non-parametric Kruskal-Wallis test was used to compare the age and BDI scores of groups. Mann-Whitney U test was used for pairwise comparisons of age, BDI and UAS7 scores. Chi-square test was used when female/male ratios were compared, and Fisher's Exact test was used if necessary conditions were not met.

25(OH)D levels were not normally distributed; after logarithmic transformation was applied, the distribution was in accordance with normality by histogram and Kolmogorov-Smirnov test. As a result, 25(OH)D levels were compared using logarithmically transformed data, but were expressed as untransformed mean \pm standard deviation for ease of understanding. Comparisons were made using the one-way ANOVA test because the logarithmic values were normally distributed and the variances were homogeneous by Levene's test. Tukey HSD test was used in post hoc evaluations because the group numbers were equal.

The correlations between 25(OH)D levels and UAS7 or BDI scores were analyzed by Spearman's correlation test. All statistical analyses were performed using SPSS 17.0 (SPSS Inc., Chicago, USA) and values of $\mathrm{p}<0.05$ were considered significant.

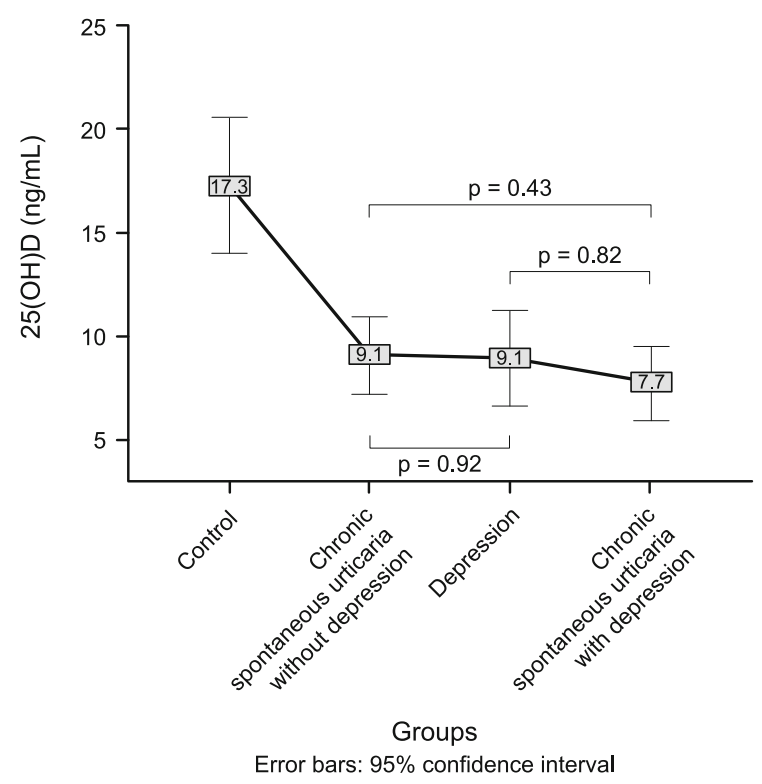

Fig. 1. 25(OH)D levels of groups. 

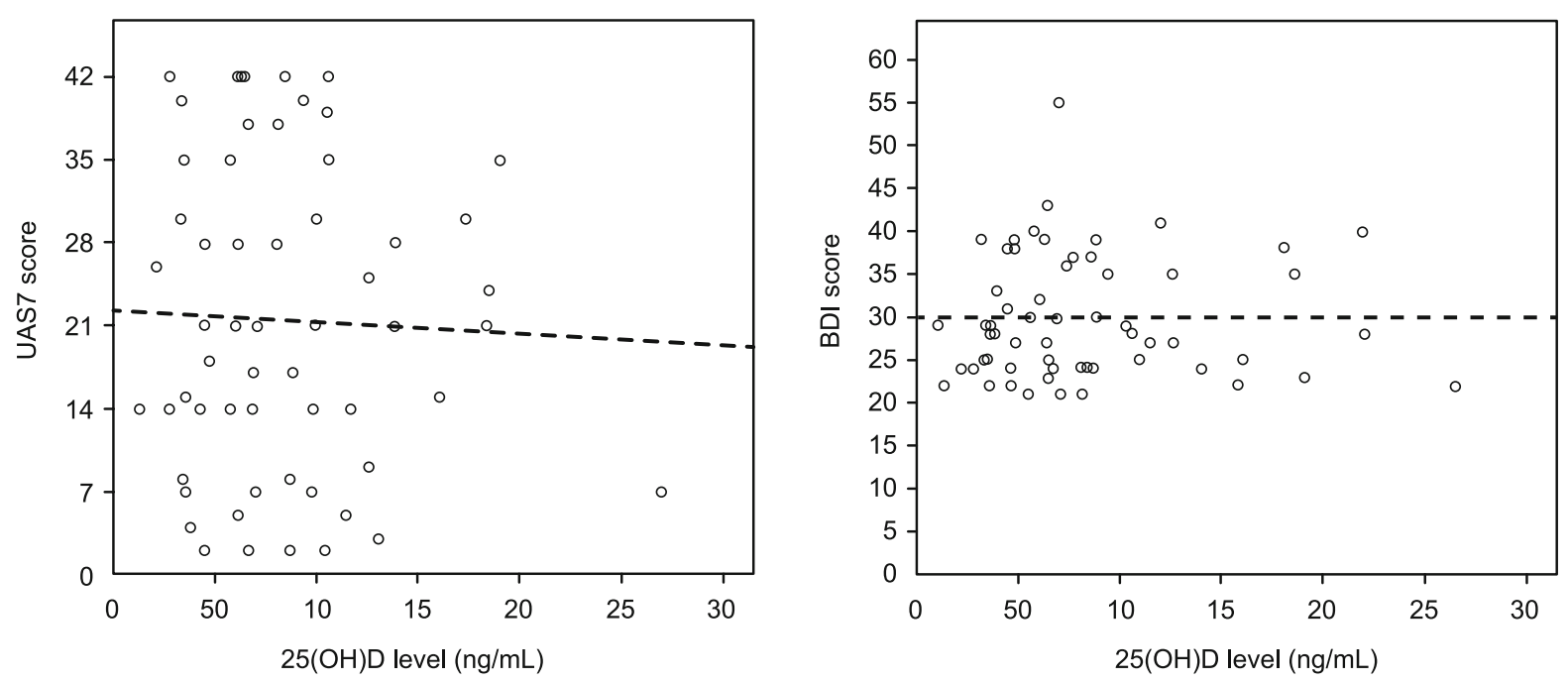

Fig. 2. Distributions of 25(OH)D levels with UAS7 (A) and BDI (B) scores with their fit lines.

\section{Results}

Demographic characteristics of control and patient groups are shown in Table 1.

Serum 25(OH)D levels were lower in all patient groups compared to the control group

Serum levels of $25(\mathrm{OH}) \mathrm{D}$ were lower in patients with CSU, depression and CSU with depression groups when compared to the control group ( $\mathrm{p}<0.001$ for each). There were no differences in $25(\mathrm{OH}) \mathrm{D}$ levels between the patient groups $(\mathrm{p}=0.92, \mathrm{p}=0.43$ and $\mathrm{p}=0.82$ ), as shown in Figure 1.

\section{Serum 25(OH)D levels were not correlated with UAS7 and BDI} scores

There were no correlations between $25(\mathrm{OH}) \mathrm{D}$ levels and UAS7 scores in all CSU patients $(r=0.002, p=0.99)$ as well as there were no correlations between $25(\mathrm{OH}) \mathrm{D}$ level and BDI scores in all depression patients $(r=0.041, p=0.76)$ as shown in Figure 2.

\section{Discussion}

In this study, 25(OH)D levels were shown to be lower in both CSU patients and depression patients compared to the healthy controls nevertheless there were no correlations between $25(\mathrm{OH})$ $\mathrm{D}$ levels and the activity of urticaria and/or depression. Vitamin $\mathrm{D}$ does not seem to be a common causative factor of CSU and depression. In recent years, $25(\mathrm{OH}) \mathrm{D}$ levels in chronic urticaria and depression have been in the focus of many researchers. Similarly, $25(\mathrm{OH}) \mathrm{D}$ levels of chronic urticaria patients have been found to be lower than in controls in studies conducted in different populations (15-20). In order to evaluate this observation, we examined the relationship between the disease activity (by UAS7) and the levels of $25(\mathrm{OH}) \mathrm{D}$ but there was no correlation between them. In concordance with our results, many of these studies haven't found any correlation between the activity of urticaria and $25(\mathrm{OH})$ D levels (15-19).

The role of vitamin D supplementation in chronic urticaria has also been investigated by researchers. Currently there is not sufficient evidence to support vitamin D supplementation in chronic urticaria patients due to the limited number of studies highlighting the benefits of vitamin D in chronic urticaria as indicated in a review by Quirk et al (21). These results do not demonstrate that vitamin $\mathrm{D}$ is involved in the etiopathogenesis of urticaria because the mechanism of action of vitamin D supplementation is not clear. These findings suggest that vitamin $\mathrm{D}$ does not interact directly with the clinical presentation of urticaria. Even so, the exact mechanism of the relevance between vitamin D deficiency and chronic urticaria remains unclear so far. As mentioned by Grzanka et al (17), lower levels of 25(OH)D may therefore appear as just a secondary phenomenon, expressed as a result of the disease process itself including inflammation or immune activation and as such, may not contribute in any way to the pathogenesis of the disease.

Consistent with our result, several studies have found lower $25(\mathrm{OH}) \mathrm{D}$ levels in depression (22-26). In order to evaluate this observation, we examined the relationship between the activity of depression (BDI score) and the levels of $25(\mathrm{OH}) \mathrm{D}$ but we found no correlation between them. Lower 25(OH)D levels were associated with an increased risk of depression as a finding in a meta-analysis (27). Nevertheless, other studies did not support this association (28-30). Only one of four meta-analyses examining the effect of vitamin D supplementation on depression has supported a beneficial effect (31). The other three meta-analyses have showed no overall beneficial effects of vitamin D supplementation (32-34). Thereby, these results do not support the findings obtained from observational studies of an important role of vitamin D in the pathogenesis of depression.

In our study, urticaria activity scores of CSU patients with depression were shown to be higher than those without. Depression accompanying urticaria in these patients may have increased the 
675-679

activity of urticaria. However, the lack of difference in 25(OH)D levels between CSU with and without depression and correlation between 25(OH)D levels and UAS7 scores indicate that the higher activity of urticaria in CSU with depression group was independent of 25(OH)D level.

Furthermore, the number of disorders associated with low levels of 25(OH)D has constantly increased (35). The discrepancy between observational studies and randomized controlled trials brings to mind that low $25(\mathrm{OH}) \mathrm{D}$ might be the result, rather than the cause, of physiological disruptions relevant to some diseases (36). From this point of view, Autier et al (35) suggest that low 25(OH) $\mathrm{D}$ could be a marker of ill health. 25(OH)D levels are significantly reduced during acute health events which are characterized by severe inflammation and multiorgan failure, especially in critically ill patients (37-38). Similar decreases in 25(OH)D levels have been reported in many inflammatory diseases (39). Inflammation appears to be the common factor of these various non-skeletal diseases. It can be speculated that vitamin D levels decreases due to the inflammatory processes occurring in the pathogenesis of the diseases and that could explain why low vitamin D status is reported in a wide range of diseases.

We have some limitations such as age differences between CSU patients and the other groups. One possible reason of this difference might be that CSU is most common between the ages 20-40 (40). However, it is not expected that there will be a physiological change in $25(\mathrm{OH}) \mathrm{D}$ levels between the ages of 32 and 40 years. $25(\mathrm{OH}) \mathrm{D}$ levels are known to be affected by age so that the levels have been shown to decrease in the elderly people ( $>$ 65 years) (41). Nevertheless, we don't think that age difference has an effect on the findings of our study because there were no elderly people ( $>65$ years), neither among patients, nor controls.

\section{Conclusion}

The results of this study have shown lower 25(OH)D levels in $\mathrm{CSU}$ and depression. There were no correlations between 25(OH) $\mathrm{D}$ levels and the activity of urticaria and/or depression. Moreover, the lack of differences in 25(OH)D levels between CSU without depression, depression and CSU with depression patients support the hypothesis that lower $25(\mathrm{OH}) \mathrm{D}$ levels in CSU and/or depression may appear as a secondary phenomenon which means to be a result of these diseases rather than the cause. In order to clarify this hypothesis, further studies are needed to monitor the vitamin D levels of CSU and depression patients before treatment and after recovery.

\section{References}

1. Braun-Falco O, Plewig G, Wolff HH, Burgdorf WHC. Urticaria, anjioedema and anaphylaxis. Dermatology. Berlin: Springer, 2000: 431-456.

2. Odom RB, James WD, Berger TG. Erythema and urticaria. Andrews Diseases of the Skinde. Philadelphia: WB Saunders Co., 2000: 146-171.

3. Sabroe RA, Greaves MW. The pathogenesis of chronic idiopathic urticaria. Arch Dermatol 1997; 133: 1003-1008.
4. Yu C, Fedoric B, Anderson PH, Lopez AF, Grimbaldeston MA. Vitamin $\mathrm{D}(3)$ signalling to mast cells: A new regulatory axis. Int J Biochem Cell Biol 2011; 43 (1): 41-46.

5. Deluca HF, Cantorna MT. Vitamin D: its role and uses in immunology. FASEB J 2001; 15 (14): 2579-2585.

6. Baroni E, Biffi M, Benigni F et al. VDR-dependent regulation of mast cell maturation mediated by 1,25-dihydroxyvitamin D3. J Leukoc Biol 2007; 81 (1): 250-262.

7. Berrino AM, Voltolini S, Fiaschi D et al. Chronic urticaria: importance of a medical-psychological approach. Eur Ann Allergy Clin Immunol 2006; 38 (5): 149-152.

8. Krishnan V, Nestler EJ. Linking molecules to mood: new insight into the biology of depression. Am J Psychiatry 2010; 167: 1305-1320.

9. Eyles DW, Smith S, Kinobe R, Hewison M, McGrath JJ. Distribution of the vitamin $D$ receptor and $1 \alpha$-hydroxylase in human brain. J Chem Neuroanat 2005; 29 (1): 21-30.

10. Fernandes de Abreu DA, Eyles D, Feron F. Vitamin D, a neuroimmunomodulator: implications for neurodegenerative and autoimmune diseases. Psychoneuroendocrinology 2009; 34 (Suppl 1): S265-277.

11. Maurer M, Metz M, Bindslev-Jensen C et al. Definition, aims, and implementation of $\mathrm{GA}^{2} \mathrm{LEN}$ urticaria centers of reference and excellence. Allergy 2016: 71; 1210-1218.

12. Beck AT, Steer RA, Brown GK. Manual for the Beck Depression Inventory-II. San Antonio, TX: Psychological Corporation; 1996.

13. Mlynek A, Zalewska-Janowska A, Martus P, Staubach P, Zuberbier T, Maurer M. How to assess disease activity in patients with chronic urticaria? Allergy 2008; 63: 777-780.

14. Goren AC, Sahin G, Gumilcineli I, Binici B. Rapid and reliable 25-OH vitamin D2 and 25-OH vitamin D3 measurements by multitasker LC-MS/MS. J Chem Metrol 2018; 12 (1): 17-25.

15. Boonpiyathad T, Pradubpongsa P, Sangasapaviriya A. Vitamin d supplements improve urticaria symptoms and quality of life in chronic spontaneous urticaria patients: a prospective case-control study. Dermatoendocrinol 2014; 6: e29727.

16. Thorp WA, Goldner W, Meza J, Poole JA. Reduced vitamin D levels in adult subjects with chronic urticaria. J Allergy Clin Immunol 2010; 126 (2): 413-414.

17. Grzanka A, Machura E, Mazur B, Misiolek M, Jochem J, Kasperski J, Kasperska-Zajac A. Relationship between vitamin D status and the inflammatory state in patients with chronic spontaneous urticaria. $\mathrm{J}$ Inflamm (Lond) 2014; 11 (1): 2.

18. Oguz Topal I, Kocaturk E, Gungor S, Durmuscan M, Sucu V, Yildirmak S. Does replacement of vitamin D reduce the symptom scores and improve quality of life in patients with chronic urticaria? J Dermato$\log$ Treat 2016; 27 (2): 163-166.

19. Hamza AM, Farid CI, Younan DN, Abd El-Wahed DS. Low levels of serum vitamin D3 in chronic spontaneous urticaria patients: relation with clinical characteristics. J Egypt Womens Dermatol Soc 2016; 13 (2): 92-98.

20. Rorie A, Goldner WS, Lyden E, Poole JA. Beneficial role for supplemental vitamin D3 treatment in chronic urticaria: a randomized study. Ann Allergy Asthma Immunol 2014; 112 (4): 376-382.

21. Quirk SK, Rainwater E, Shure AK, Agrawal DK. Vitamin D in atopic dermatitis, chronic urticaria and allergic contact dermatitis. Expert Rev Clin Immunol. 2016; 12: 839-847. 
22. Hoogendijk WJ, Lips P, Dik MG, Deeg DJ, Beekman AT, Penninx BW. Depression is associated with decreased 25-hydroxyvitamin D and increased parathyroid hormone levels in older adults. Arch Gen Psychiatry 2008; 65 : 508-512.

23. Jorde R, Waterloo K, Saleh F, Haug E, Svartberg J. Neuropsychological function in relation to serum parathyroid hormone and serum 25-hydroxyvitamin D levels. J Neurol 2006; 253: 464-470.

24. Jaddou HY, Batieha AM, Khader YS, Kanaan SH, El-Khateeb MS, Ajlouni KM. Depression is associated with low levels of 25-hydroxyvitamin D among Jordanian adults: results from a national population survey. Eur Arch Psychiatry Clin Neurosci 2012; 262: 321-327.

25. Polak MA, Houghton LA, Reeder AI, Harper MJ, Conner TS. Serum 25-hydroxyvitamin D concentrations and depressive symptoms among young adult men and women. Nutrients 2014; 6: 4720-4730.

26. Black LJ, Jacoby P, Allen KL et al. Low vitamin D levels are associated with symptoms of depression in young adult males. Aust N Z J Psychiatry 2014; 48: 464-471.

27. Ju SY, Lee YJ, Jeong SN. Serum 25-hydroxyvitamin D levels and the risk of depression: a systematic review and meta-analysis. J Nutr Health Aging 2013; 17: 447-455.

28. Zhao G, Ford ES, Li C, Balluz LS. No associations between serum concentrations of 25-hydroxyvitamin D and parathyroid hormone and depression among US adults. Br J Nutr 2010; 104: 1696-1702.

29. Nanri A, Mizoue T, Matsushita Y, Poudel-Tandukar K, Sato M, Ohta M, Mishima N. Association between serum 25-hydroxyvitamin D and depressive symptoms in Japanese: analysis by survey season. Eur J Clin Nutr 2009; 63: 1444-1447.

30. Pan A, Lu L, Franco OH, Yu Z, Li H, Lin X. Association between depressive symptoms and 25-hydroxyvitamin D in middle-aged and elderly Chinese. J Affect Disord 2009; 118: 240-243.
31. Spedding S. Vitamin D and depression: a systematic review and metaanalysis comparing studies with and without biological flaws. Nutrients 2014; 6: 1501-1518.

32. Li G, Mbuagbaw L, Samaan Z et al. Efficacy of vitamin D supplementation in depression in adults: a systematic review. J Clin Endocrinol Metab 2014; 99: 757-767.

33. Shaffer JAP, Edmondson D, Wasson LT et al. Vitamin D Supplementation for Depressive Symptoms: A Systematic Review and Meta-Analysis of Randomized Controlled Trials. Psychosom Med 2014; 76: 190-196.

34. Gowda U, Mutowo MP, Smith BJ, Wluka AE, Renzaho AMN. Vitamin D supplementation to reduce depression in adults: Meta-analysis of randomized controlled trials. Nutrition 2015; 31: 421-429.

35. Autier P, Boniol M, Pizot C, Mullie P. Vitamin D status and ill health: a systematic review. Lancet Diabetes Endocrinol 2014; 2 (1): 76-89.

36. Harvey NC, Cooper C. Vitamin D: some perspective please. BMJ 2012; 345: e4695.

37. Van den Berghe G, Van Roosbroeck D, Vanhove P, Wouters PJ, De Pourcq L, Bouillon R. Bone turnover in prolonged critical illness: effect of vitamin D. J Clin Endocrinol Metab 2003; 88: 4623-4632.

38. Lee P, Eisman JA, Center JR. Vitamin D deficiency in critically ill patients. N Engl J Med 2009; 360: 1912-1914.

39. Yin K, Agrawal DK. Vitamin D and inflammatory diseases. J Inflamm Res 2014; 7: 69-87.

40. Zuberbier T, Maurer M. Urticaria: current opinions about etiology, diagnosis and therapy. Acta Derm Venereol 2007; 87: 196-205.

41. Gallagher JC. Vitamin D and aging. Endocrinol Metab Clin North Am 2013; 42 (2): 319-332.

Received April 11, 2020. Accepted May 12, 2020. 